\title{
Authors' Reply to Alatorre et al.: "Cost Effectiveness of Guanfacine Extended-Release Versus Atomoxetine for the Treatment of Attention-Deficit/Hyperactivity Disorder: Application of a Matching-Adjusted Indirect Comparison"
}

\author{
M. Haim Erder $\cdot$ Jipan Xie $\cdot$ James E. Signorovitch $\cdot$ \\ Kristina S. Chen • Paul Hodgkins • Mei Lu • \\ Eric Q. Wu • Vanja Sikirica \\ Published online: 17 April 2013 \\ (C) The Author(s) 2013. This article is published with open access at Springerlink.com
}

We thank Dr Alatorre and co-authors for their letter [1] regarding our manuscript entitled "Cost effectiveness of guanfacine extended-release versus atomoxetine for the treatment of attention-deficit/hyperactivity disorder: application of a matching-adjusted indirect comparison", which was published in the November 1, 2012 issue of Applied Health Economics and Health Policy [2].

We have conducted a thorough review of the manuscript and supportive study analyses from which it stems. We have found that some numbers in Table III were transposed in the published manuscript. The erratum [3] is published to correct these errors.

We apologize for the errors and confirm that these errors are typographical in nature and do not affect the results, discussion or conclusion in the originally published manuscript [2].

Open Access This article is distributed under the terms of the Creative Commons Attribution Noncommercial License which permits any noncommercial use, distribution, and reproduction in any medium, provided the original author(s) and the source are credited.
The exclusive right to any commercial use of the article is with Springer.

\section{References}

1. Alatorre CI, Haynes V, Faries D, Upadhyaya H, Kelsey D. Cost effectiveness of guanfacine extended-release versus atomoxetine for the treatment of attention-deficit/hyperactivity disorder: application of a matching-adjusted indirect comparison [letter]. Appl Health Econ Health Policy. 2013. doi:10.1007/s40258-013-0024-2.

2. Erder MH, Xie J, Signorovitch JE, Chen KS, Hodgkins P, Lu M, Wu EQ, Sikirica V. Cost effectiveness of guanfacine extendedrelease versus atomoxetine for the treatment of attention-deficit/ hyperactivity disorder: application of a matching-adjusted indirect comparison. Appl Health Econ Health Policy. 2012;10(6):381-95.

3. Erder MH, Xie J, Signorovitch JE, Chen KS, Hodgkins P, Lu M, Wu EQ, Sikirica V. Erratum to: cost effectiveness of guanfacine extended-release versus atomoxetine for the treatment of attentiondeficit/hyperactivity disorder: application of a matching-adjusted indirect comparison. Appl Health Econ Health Policy. 2013. doi: 10.1007/s40258-013-0015-3.

This Correspondence refers to the article at doi:10.1007/s40258-013-0024-2

M. H. Erder · K. S. Chen · P. Hodgkins · V. Sikirica $(\bowtie)$

Shire Development LLC, 725 Chesterbrook Blvd, Wayne, PA 19087, USA

e-mail: vsikirica@shire.com

J. Xie · J. E. Signorovitch - M. Lu · E. Q. Wu

Analysis Group, Inc., Boston, MA, USA 